\title{
Preserving the fire: Some thoughts on traditional attire of Bagri females
}

\section{Mamta and Harminder Kaur Saini}

Received: 14.07.2020; Revised: 20.10.2020; Accepted: 03.11.2020

See end of the paper for authors' affiliations

\section{Mamta}

Department of Apparel and

Textile Science, College of

Home Science, Punjab

Agriculture University, Ludhiana

(Punjab) India

Email : mamtasaharan-ats@pau.

edu
ABSTRACT : The past few decades witnessed some developments that have left a permanent mark on the life style and costumes. The traditional costumes, jewellery and other accessories as well as a traditional lifestyle have been adversely affected by various factors of the social change process and vanished into the antiquity. It is significant to document this heritage for posterity and conservation of our age-old rich traditions. The purpose of this study was to explore and document the attire of Bagri females of North Western India. Interview questions were mainly focused on specific information related to the upper and lower garments, headdresses and jewellery and body decoration. Findings of the study revealed that most preferred traditional dresses of Bagri females were Aangi, Jamper, Ghaghro, Bugiyo, Sunkukdo, Chundadi and Pila. In the fashion market, there are some contemporary designs of dresses and jewellery available which shows similarity with Bagri attire.

KEY WORDS: Bagri, Attire, Culture, Female, Traditional

- HOW TO CITE THIS PAPER : Mamta and Saini, Harminder Kaur (2020). Preserving the fire: Some thoughts on traditional attire of Bagri females. Asian J. Home Sci., 15 (2) : 247-254, DOI: 10.15740/HAS/ AJHS/15.2/247-254. Copyright@ 2020: Hind Agri-Horticultural Society. 